consolidate the abstracting services now carried on independently in many countries, a measure that could reduce present duplication of effort by a conservatively estimated factor of three.

The publication of international review journals of two types as follows is recommended: interdisciplinary review journals written in relatively nontechnical language for the benefit of scientists in different disciplines, and more specialized review journals which would keep scientists working in a given area abreast of the work going on in the same or related areas all over the world.

All Governments are recommended to open their postal systems to the untrammelled flow of scientific publications whatever their country of origin or destination.

\title{
LAND USE IN ARID REGIONS
}

$\mathrm{T}$ HE arid zone programme of the United Nations Educational, Scientific and Cultural Organiza. tion, one of the Organization's three major projects, has yielded several valuable reviews of research and proceedings of symposia, mostly devoted to hydrology and ecology. The latest in the series, a volume of some 350,000 words reviewing the history of land use in arid regions, is of more general interest *. It deals with all the main dry lands with two main exceptions, those surrounding Abyssinia and those of South America in post-Columbian times.

F. K. Hare explains the widespread aridity in sub. tropical latitudes in terms of the divergent wind-flow at low levels related to high pressure at $2-3 \mathrm{~km}$., and considers it unlikely that any past climatic epoch can have been free of tropical aridity. He finds it inconceivable that man can significantly alter the régime, the energy transformations involved are on so large a seale. Thus the flooding of desert depressions, for example, would have only very modest effects on neighbouring areas.

A summary by K. W. Butzer of what is known about elimatic change in arid lands since the Pliocene sets the regional histories in a longer time perspective. Full aridity was achieved in most arid lands some 15,000 years ago. Since then there has been no progressive desiccation, only minor fluctuations of climate. Of especial interest are those fluctuations which might possibly have affected the environment of man when he was first beginning to manage crops and animals in south-west Asia ten thousand years ago and in Mexico possibly not much later.

Changes in climate over the past two or three thousand years are scarcely detectable with certainty until the fluctuation of the past three centuries. This has involved more than the spectacular rapid advance and current retreat of Alpine glaciers, for it is becoming clear that semi-arid lands in many parts of the world have been receiving less rain in recent decades than in the latter half of the nineteenth century. The dry trend continues, and the further outlook is unsettled.

Prof. Dudley Stamp, the editor of the volume, points out that a knowledge of the climate is not enough to allow a reconstruction of the past vegetation cover. The effects of burning and of a more prolific fauna have also to be taken into account. Ecologists and archæologists working together in the field are beginning to produce fairly reliable pictures of ancient landscapes, and R. O. Whyte, in his contribution on south-east Asia, sees much promise in this type of co-operative research.

South-west Asia is in many ways the most important of the regions and at the same time it produces *United Nations Educational, Scientiflc and Cultural Organization. Arid Zone Research No. 17: A History of Land Use in Arid Regions. Edited by L. Dudley Stamp. Pp. 388. (Paris: Unesco; London: H.M.S.O., 1961.) 37 N.F.; 528. $6 d$.; 10.50 dollars. the greatest difficulties in comprehension because of the mass of information available from widely scattered sites and conflicting interpretations of evidence. Whyte's review is very stimulating but not at all easy to digest. Egypt is of its nature simpler, and the material presented by G. Hamdan will be more familiar to many readers. V. A. Kovda's survey of the Russian plains, the Caucasus and Central Asia (plus a few pages on irrigation in China) naturally lays great stress on the revolutionary effects of introducing socialist methods of production to the steppe. The scale of operations is indeed impressive. Kovda notes the steady increase in the frequency of sukhovei, dry dusty winds, but asserts that their effects will be mitigated by new forests and irrigation projects which, he says, are expected to increase precipitation.

J. Despois, writing on North Africa, agrees with Butzer that there is no good evidence that the climate there was much more favourable to farming in the Roman period than in later times. The decline in agriculture can mainly be attributed to eleventhcentury and later invasions of Bedouin Arabs from the east. Even their destructiveness seems to have been far exceeded by those other nomadic herdsmen, the Mongols, who descended on western Asia two centuries later. From both, recovery was slow, and in Cyrenaica and parts of Iraq and Iran is atill incom. plete.

Nomadism is a rational response to those seasonal and year-to-year variations in grazing and surface water typical of arid regions. R. F. Logan describes flocks in the United States being driven in double. decker trucks to summer grazing in upland meadows under Forest Service permits. Everywhere some State control of nomadism seems to be inevitable. Although, as Th. Monod and Ch. Toupet note in the Saharan region, an irreversible process of "sedenterization" has set in since pacification, progress in this direction is likely to be too slow to satigfy administra. tors and conservationists.

Innovations bring old problems. Perennial irriga. tion can lead to salt accumulation and waterlogging, as in the Punjab, and to bilharzia and other diseases. Improved water supplies from deep wells can accentuate overgrazing. The balance is delicate in arid lands and the regulating mechanism must work efficiently or disaster comes swiftly. This seems to be the main lesson to be learned from the past.

For the future, the possibilities of industry based. on local minerals, with space-cooling and a sunny climate to attract labour, are becoming apparent from recent developments in Arizona and Central Asia. The process of urbanization is not new to the arid lands, it probably began there, and may well go further there than anywhere else in the world.

A. T. Grove 